\title{
Optical Properties of Multi-Stacked InAs Quantum Dots Embedded in GaAs/InGaAs Strained Layer and its Annealing Behaviors
}

\author{
D.Y. KIM ${ }^{a}$, G.S. KIM ${ }^{a}$, S.M. JeON ${ }^{a}$, M.Y. ChO ${ }^{a}$, H.Y. CHOI ${ }^{a}$, M.S. KIM ${ }^{a}$, D.-Y. LeE ${ }^{b}$ \\ J.S. KIM ${ }^{c}$, J.S. KIM ${ }^{d}$, G.-S. EOM ${ }^{e}$, J.-Y. LEEM ${ }^{a, *}$ \\ ${ }^{a}$ Center for Nano Manufacturing, Inje University, Gimhae 621-749, Korea \\ ${ }^{b}$ Lighting Module Research and Development, Samsung Electro-Mechanics Co., Ltd., Suwon 443-373, Korea \\ ${ }^{c}$ Division of Advanced Materials Engineering, Chonbuk National University, Jeonju 561-756, Korea \\ ${ }^{d}$ Department of Physics, Yeungnam University, Gyeongsan 712-749, Korea \\ ${ }^{e}$ Division of General Education, Uiduk University, Gyeongju 780-713, Korea
}

(Received June 18, 2009)

\begin{abstract}
Multi-stacked InAs QDs embedded in ten periods of GaAs/ $\operatorname{In}_{0.1} \mathrm{Ga} 0.9$ As strained layers were grown by $\mathrm{MBE}$ and their optical properties were investigated by using PL spectroscopy. For the QDs embedded in ten periods of $\mathrm{GaAs} / \mathrm{In}_{0.1} \mathrm{Ga}_{0.9} \mathrm{As}$ strained layers, the PL intensity is enhanced about 4.7 times and a narrower FWHM of $26 \mathrm{meV}$ is observed compared to those of the conventional multi-stacked QDs. The PL spectra of the InAs QDs show blue-shifts of about $50 \mathrm{meV}$ with increasing annealing temperature up to $850^{\circ} \mathrm{C}$. At annealing temperature of $600^{\circ} \mathrm{C}$, the FWHM of the PL peak is reduced to $16 \mathrm{meV}$ and PL intensity is enhanced compared to those of the as-grown sample, which indicates improvement of size uniformity and crystal quality of the QDs.
\end{abstract}

PACS numbers: 78.67.Hc, 78.55.Cr, 81.05.Ea

\section{Introduction}

Over the past several years, a three-dimensional quantum-confined structure, quantum dot (QD), has attracted considerable interest from both fundamental physics and potential device applications [1-6]. For example, a QD laser diode is expected to have high thermal stability, a low threshold current density, and a high gain due to the unique properties of QDs, atomic-like electronic states, and a delta-function-like density of states. Among the techniques for fabricating QDs, the StranskiKrastanov ( $\mathrm{S}-\mathrm{K}$ ) growth method can be one promising path for the creation of a damage free formation of dot structures directly on the epilayer surface [7]. However, InAs/GaAs QDs grown via $\mathrm{S}-\mathrm{K}$ growth method revealed large inhomogeneous broadening in the optical emission ranging from 50 to $90 \mathrm{meV}$. In order to achieve high uniformity in QDs size and shape, various growth parameters such as growth temperature, deposition rate, growth interruption group III/V ratio strain, and composition of structure layers, which affect the QD structures and their

\footnotetext{
* corresponding author; e-mail: jyleem@inje.ac.kr
}

optoelectronic properties, have been employed so far in lots of researches [5, 8-10].

On the other hand, one of the challenging technological issues today is to increase the total QD densities while maintaining the quality and uniformity of QD structures. It is known that stacking of QDs by $\mathrm{S}-\mathrm{K}$ growth method in Molecular Beam Epitaxy (MBE) is a powerful way of increasing the QD density. In the stacking process, however, the strain is stored because the host material used for burying QDs is generally the same as substrate and hence, the stress generated by QDs cannot be compensated. In stacking of InAs/GaAs QDs, it is commonly observed that the size of QDs increases considerably when going from the bottom to the top layer, leading to a red shift of the emission wavelength [11-14]. To overcome the problems of QDs size inhomogeneity in the stacked structures, In-flush method and closely stacked QD structures have been proposed [11, 14-16]. Recently, we have demonstrated the effects of a GaAs/InGaAs strained layer on the optical properties of 3 monolayers (ML) of single InAs QDs on GaAs substrates. The results showed that InAs QDs with narrow photoluminescence (PL) linewidth could be realized by employing a GaAs/InGaAs strained layer [17]. 
In this work, multi-stacked InAs QDs embedded in ten periods of $\mathrm{GaAs} / \mathrm{In}_{0.1} \mathrm{Ga}_{0.9} \mathrm{As}$ strained layer were grown by MBE, and their optical properties were investigated by using PL spectroscopy. Optical properties of multi-stacked InAs QDs embedded in ten periods of GaAs/ $\mathrm{In}_{0.1} \mathrm{Ga}_{0.9}$ As strained layer were improved compared to those of conventional multi-stacked InAs QDs.

\section{Experimental details}

The InAs QDs were grown on semi-insulating GaAs (001) substrates using the MBE system (RIBER32P). Three different samples were grown by varying the QDs size and thickness of GaAs spacer layers. Figure 1 shows the cross-sectional schematic diagram of five-stacked $\operatorname{InAs}(x \mathrm{ML}) / \mathrm{GaAs}(y \mathrm{~nm})$ QDs embedded in ten periods of $\operatorname{GaAs}(2 \mathrm{~nm}) / \operatorname{In}_{0.1} \mathrm{Ga}_{0.9} \mathrm{As}(2 \mathrm{~nm})$ strained layer. For the three different samples, the QDs size and thickness of GaAs spacer layers are as follows: $(x, y)=(3 \mathrm{ML}, 2 \mathrm{~nm})$, (3 ML, $3 \mathrm{~nm})$, and (2 ML, $3 \mathrm{~nm})$, which are denoted as the QD1, QD2 and QD3 samples, respectively. After the deoxidization of the substrate at $540{ }^{\circ} \mathrm{C}$, the GaAs buffer layer with a thickness of $500 \mathrm{~nm}$ was grown on the substrate at $560^{\circ} \mathrm{C}$. Then, the substrate temperature was lowered to $460{ }^{\circ} \mathrm{C}$ for the five-stacked InAs/GaAs QDs and ten periods of $\mathrm{GaAs} / \mathrm{In}_{0.1} \mathrm{Ga}_{0.9}$ As strained layer. For a sufficient migration time of In adatom, the growth interruption time was $30 \mathrm{~s}$ before and after the formation of each InAs QD layer. A GaAs capping layer with a thickness of $25 \mathrm{~nm}$ was grown on the ten periods of GaAs/ $\mathrm{In}_{0.1} \mathrm{Ga}_{0.9}$ As strained layer. The rapid thermal annealing (RTA) treatments on the five-stacked InAs/GaAs QDs embedded in the lower $\mathrm{GaAs} / \mathrm{In}_{0.1} \mathrm{Ga}_{0.9} \mathrm{As}$ and the upper GaAs/ $/ \mathrm{In}_{0.1} \mathrm{Ga}_{0.9}$ As strained layer were performed at temperature range from 600 to $850{ }^{\circ} \mathrm{C}$ for $30 \mathrm{~s}$ in a nitrogen atmosphere to suppress oxidation of the surface. Before RTA treatments, samples cut from the central region of the wafer were capped with bulk GaAs so that As would not be removed from the surface.

In the PL measurement, an Argon-ion laser with a wavelength of $514.5 \mathrm{~nm}$ was used as an excitation source to generate electron-hole pairs. Luminescence light from the sample was focused with collection lenses, dispersed by a $1 \mathrm{~m}$ monochromator, and detected by a liquidnitrogen cooled Ge detector.

\section{Results and discussion}

Figure 2 shows the $11 \mathrm{~K}$ PL spectra of five-stacked InAs QDs embedded in ten periods of $\mathrm{GaAs} / \mathrm{In}_{0.1} \mathrm{Ga}_{0.9} \mathrm{As}$ strained layer. For the QD1 sample with the $3 \mathrm{ML}$ thick InAs QDs and $2 \mathrm{~nm}$ thick GaAs spacer, the PL peak energy of the InAs QDs is $1.111 \mathrm{eV}$. As the thickness of GaAs spacer increases from 2 to $3 \mathrm{~nm}$, the PL peak energy of the InAs QDs is blue-shifted to $1.143 \mathrm{eV}$ (QD2 sample). The PL peak energy of the InAs QDs is more blue-shifted to $1.152 \mathrm{eV}$ (QD3 sample) with decreasing the InAs QDs size from 3 to 2 ML. These results are

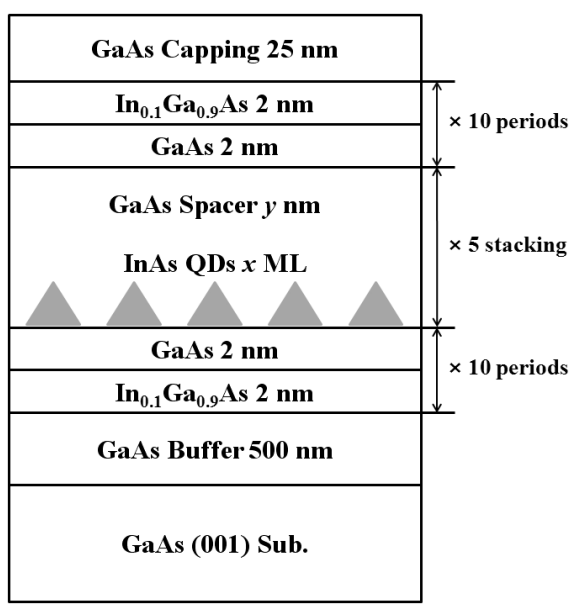

Fig. 1. Cross-sectional schematic diagram of five-stacked InAs QDs embedded in ten periods of GaAs/ $\mathrm{In}_{0.1} \mathrm{Ga}_{0.9}$ As strained layer.

similar with conventional multi-stacked InAs/GaAs QDs $[16,18-20]$. The full width at half maximum (FWHM) of the PL peak is $55 \mathrm{meV}$ for QD1 sample, $31 \mathrm{meV}$ for QD2 sample, and $26 \mathrm{meV}$ for QD3 sample, respectively, as shown in the inset of Fig. 2. The narrower FWHM can be explained by homogenization of the sizes for the individual InAs QDs. That is, a narrower FWHM of the PL peak for QD ensembles correlates with a uniform size distribution. A narrow PL linewidth can contribute to improvements in some performance characteristics of QD opto-electronic devices [21].

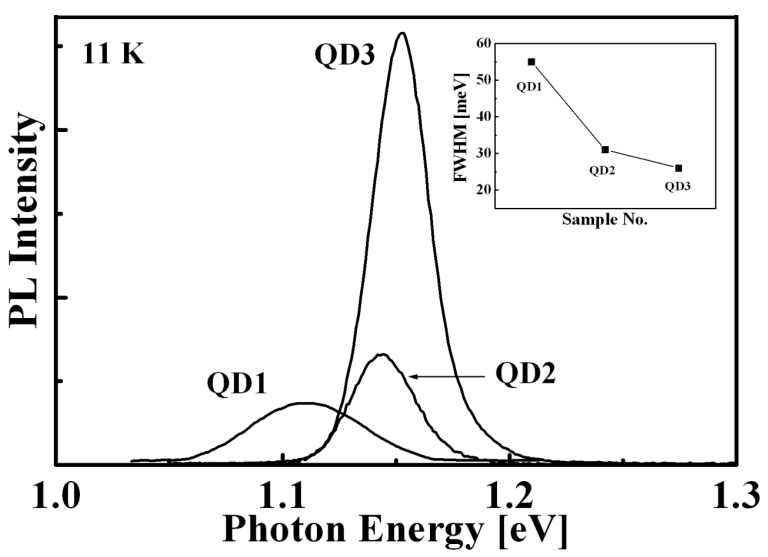

Fig. 2. PL spectra $(11 \mathrm{~K})$ of the QD1, QD2, and QD3 samples. The inset shows the FWHM of the PL peak from each QDs sample.

In order to investigate the effects of GaAs/ $\mathrm{In}_{0.1} \mathrm{Ga}_{0.9}$ As strained layer on InAs QDs, we grew another sample (denoted as the QD4 sample), whose layer structures are almost the same as QD3 sample, except that ten periods of $\mathrm{GaAs} / \mathrm{In}_{0.1} \mathrm{Ga}_{0.9} \mathrm{As}$ strained layer were not deposited. Figure 3 shows the $11 \mathrm{~K}$ PL spectra of QD3 and QD4 samples. An obvious narrowing of the 


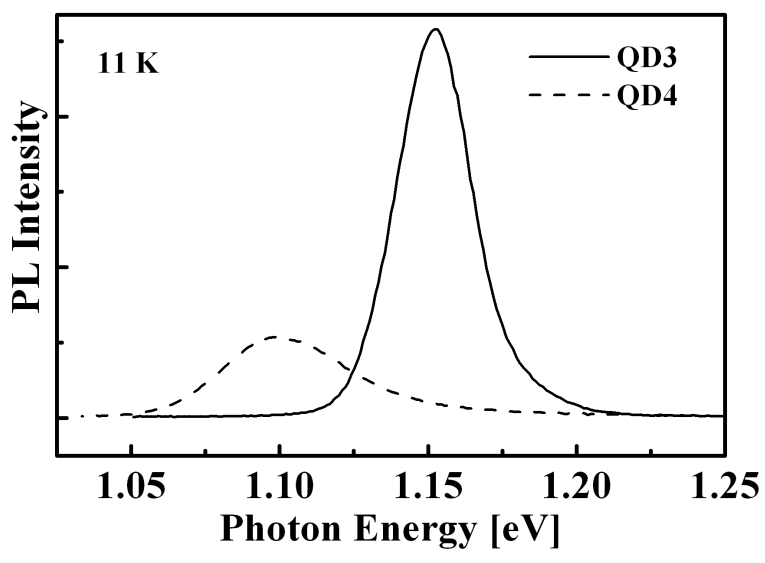

Fig. 3. PL spectra $(11 \mathrm{~K})$ of the QD3 sample with GaAs/ $\mathrm{In}_{0.1} \mathrm{Ga}_{0.9}$ As strained layer and the QD4 sample without GaAs $/ \mathrm{In}_{0.1} \mathrm{Ga}_{0.9}$ As strained layer.

FWHM is observed from $43 \mathrm{meV}$ for the QD4 sample to $26 \mathrm{meV}$ for the QD3 sample. And the PL intensity of the QD3 sample is enhanced about 4.7 times compared to that of the QD4 sample. A narrower FWHM and higher PL intensity are regarded as a clear evidence for the improvement of crystal quality. In the growth of InAs QDs on GaAs via a conventional growth structure, i.e., a single or a multilayered InAs/GaAs structure, there might be defects between the atoms on either side of the interface due to the large strain. In the case of InAs QDs grown on ten periods of GaAs $/ \mathrm{In}_{x} \mathrm{Ga}_{1-x}$ As strained layer, the lattice mismatch is much smaller than that of the InAs QDs directly grown on GaAs. In addition, the transfer of defects from the buffer layer can be effectively suppressed toward other regions by the strained multilayers of GaAs $/ \mathrm{In}_{0.1} \mathrm{Ga}_{0.9}$ As. These effects can effectively suppress the formation of mismatch dislocations [17].

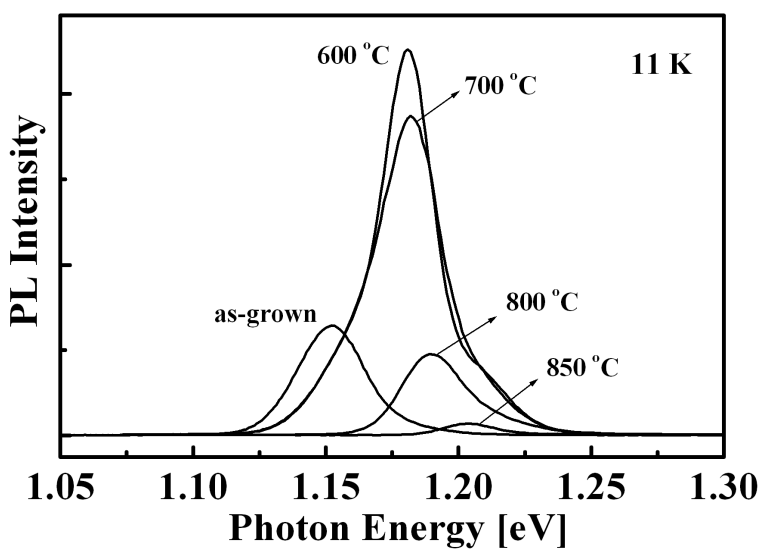

Fig. 4. PL spectra $(11 \mathrm{~K})$ of the QD3 samples annealed at temperature range from 600 to $850{ }^{\circ} \mathrm{C}$.

Figure 4 shows the $11 \mathrm{~K}$ PL spectra obtained from the QD3 samples with the 2 ML thick InAs QDs and $3 \mathrm{~nm}$ thick GaAs spacer annealed at temperature range from
600 to $850{ }^{\circ} \mathrm{C}$. The PL spectra denoted by as-grown is for the unannealed sample. At annealing temperature of $600{ }^{\circ} \mathrm{C}$, the PL intensity is enhanced about 3.5 times compared to that of the as-grown sample. The increase in the PL intensity at temperature of $600^{\circ} \mathrm{C}$ is regarded as being due to a reduction of the non-radiative recombination centers. Then the PL intensity decreases with increasing annealing temperature. The PL intensity of the samples annealed at 800 and $850^{\circ} \mathrm{C}$ is smaller than that of the as-grown sample. Too high annealing temperature would either destroy the dots or introduce non-radiative recombination centers usually as dislocation into the QD system, which decreases the PL intensity of the samples dramatically.

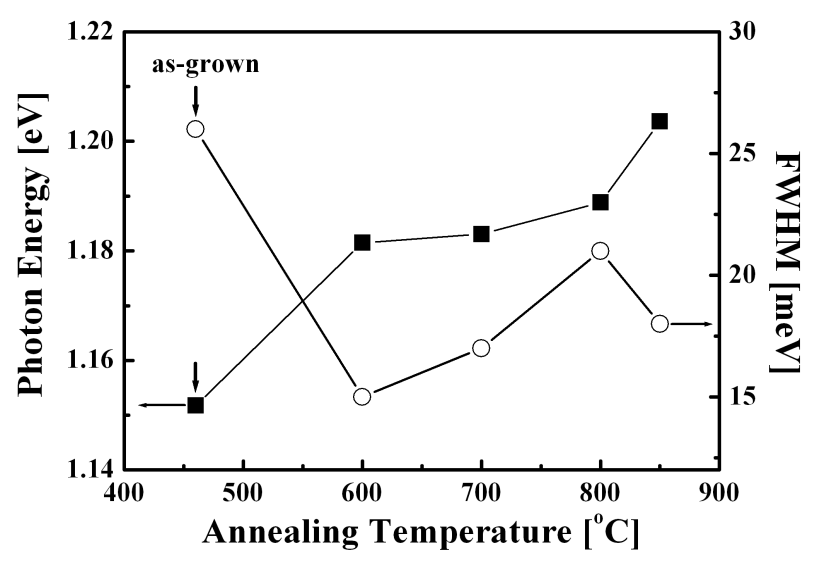

Fig. 5. The PL peak energy (filled squares) and the FWHM (open circles) of the QD3 samples as a function of annealing temperature.

The PL peak energy and the FWHM from each QDs sample are summarized in Fig. 5. As the annealing temperature is increased up to $850^{\circ} \mathrm{C}$, a relatively small blue-shift of about $50 \mathrm{meV}$ of the PL peak is observed, which indicates a very weak interdiffusion of In and Ga atoms at the interface between the QDs and the GaAs/ $\mathrm{In}_{0.1} \mathrm{Ga}_{0.9}$ As strained layer. In previous work, in the case of the single InAs QDs embedded in ten periods of GaAs/ $\mathrm{In}_{0.1} \mathrm{Ga}_{0.9}$ As strained layer, the PL peak position of the QDs was blue-shifted about $100 \mathrm{meV}$ as the annealing temperature was increased up to $850^{\circ} \mathrm{C}$ [17]. The blue-shift in the emission energy could be suppressed by increasing the stacking number of InAs QDs. The suppression of the blue-shift is attributed to reduced interdiffusion of In atoms under the strain field within or nearby the QDs [16]. By annealing treatment, the FWHM of the $\mathrm{PL}$ peak is decreased compared to that of the as-grown sample. At annealing temperature of $600^{\circ} \mathrm{C}$, the FWHM of the PL peak is $16 \mathrm{meV}$, which indicates improvement of size uniformity of the QDs. Then the FWHM of the PL peak increases with increasing the annealing temperature. The broadening of the FWHM of the PL peak can be attributed to an inhomogeneous interdiffusion of In and Ga atoms at higher annealing temperature. These 
results are similar to the change of the PL intensity as it is shown in Fig. 4.

\section{Conclusions}

The effects of $\mathrm{GaAs} / \mathrm{In}_{0.1} \mathrm{Ga}_{0.9} \mathrm{As}$ strained layer on optical properties of multi-stacked InAs QDs were investigated by $\mathrm{PL}$ measurements. Optical properties of the InAs QDs were improved by inserting ten periods of GaAs/ $\mathrm{In}_{0.1} \mathrm{Ga}_{0.9}$ As strained layer. At annealing temperature of $600^{\circ} \mathrm{C}$, the PL intensity was enhanced about 3.5 times and a narrower FWHM of $16 \mathrm{meV}$ was obtained compared to those of the as-grown sample. A higher PL intensity and narrower FWHM are regarded as a clear evidence for the improvement of crystal quality, which can contribute to improvements in some performance characteristics of QD opto-electronic devices.

\section{Acknowledgments}

This work was supported by the Korea Research Foundation (KRF) grant funded by the Korea government (MEST) (No. 2009-0072533)

\section{References}

[1] F. Klopf, J.P. Reithmaier, A. Frochel, Appl. Phys. Lett. 77, 1419 (2000).

[2] H.S. Kim, J.H. Suh, C.G. Park, S.J. Lee, S.K. Noh, J.D. Song, Y.J. Park, W.J. Choi, J.I. Lee, J. Crystal Growth 311, 258 (2009).

[3] J.S. Kim, D.K. Oh, P.W. Yu, J.-Y. Leem, J.I. Lee, C.-R. Lee, J. Crystal Growth 261, 38 (2004).

[4] R. Nedzinskas, B. Cechavicius, J. Kavaliauskas, V. Karpus, G. Krivaite, V. Tamosiunas, G. Valusis, F. Schrey, K. Unterrainer, G. Strasser, Acta Phys. Pol. A 113, 975 (2008).

[5] J.S. Kim, J.H. Lee, S.U. Hong, W.S. Han, H.-S. Kwack, C.W. Lee, D.K. Oh, J. Appl. Phys. 94, 6603 (2003).

[6] Y. Yang, B. Jo, J. Kim, K.J. Lee, M. Ko, C.-R. Lee, J.S. Kim, D.K. Oh, J.S. Kim, J.-Y. Leem, Thin Solid Films 517, 3979 (2009).

[7] C.W. Snyder, B.G. Orr, D. Kessler, L.M. Sander, Phys. Rev. Lett. 66, 3032 (1991).
[8] Y. Lee, E. Ahn, J. Kim, P. Moon, C. Yang, E. Yoon, H. Lim, H. Cheong, Appl. Phys. Lett. 90, 033105 (2007).

[9] T. Yang, J. Tatebayashi, S. Tsukamoto, M. Nishioka, Y. Arakawa, Appl. Phys. Lett. 84, 2817 (2004).

[10] C.Y. Park, J.M. Kim, K.W. Park, J.S. Yu, Y.T. Lee, Physica E 40, 3160 (2007).

[11] Y. Nakata, Y. Sugiyama, T. Futatsugi, N. Yokoyama, J. Crystal Growth 175/176, 713 (1997).

[12] G.S. Solomon, J.A. Trezza, A.F. Marshall, J.S. Harris Jr., Phys. Rev. Lett. 76, 952 (1996).

[13] M. Grundmann, N.N. Ledentsov, F. Hopfer, F. Heinrichsdorff, F. Guffarth, D. Bimberg, V.M. Ustinov, A.E. Zhukov, A.R. Kovsh, M.V. Maximov, Y.G. Musikhin, Z.I. Alferov, J.A. Lott, N.D. Zhakharov, P. Werner, J. Mater. Sci. Mater. Electron. 13, 643 (2002).

[14] P. Hazdra, J. Voves, J. Oswald, K. Kuldova, A. Hospodkova, E. Hulicius, J. Pangrac, Microelectron. J. 39, 1070 (2008).

[15] Z.R. Wasilewski, S. Fafard, J.P. McCaffrey, J. Crystal Growth 201/202, 1131 (1999).

[16] J. Tatebayashi, Y. Arakawa, N. Hatori, H. Ebe, M. Sugawara, H. Sudo, A. Kuramata, Appl. Phys. Lett. 85, 1024 (2004).

[17] D.Y. Kim, M.S. Kim, T.H. Kim, G.S. Kim, H.Y. Choi, M.Y. Cho, H.H. Ryu, W.W. Park, D.Y. Lee, J.S. Kim, J.S. Kim, J.S. Son, J.Y. Leem, J. Korean Phys. Soc. 54, 180 (2009).

[18] M.O. Lipinski, H. Schuler, O.G. Schmidt, K. Eberl, N.Y. Jin-Phillipp, Appl. Phys. Lett. 77, 1789 (2000).

[19] N.N. Ledentsov, V.A. Shchukin, M. Grundmann, N. Kirstaedter, J. Bohrer, O. Schmidt, D. Bimberg, V.M. Ustinov, A.Yu. Egorov, A.E. Zhukov, P.S. Kop'ev, S.V. Zaitsev, N.Yu. Gordeev, Zh.I. Alferov, A.I. Borovkov A.O. Kosogov, S.S. Ruvimov, P. Werner, U. Gosele, J. Heydenreich, Phys. Rev. B 54, 8743 (1996).

[20] J.C. Gonzalez, F.M. Matinaga, W.N. Rodrigues, M.V.B. Moreira, A.G. de Oliveira, Surf. Sci. 482-485, 836 (2001).

[21] N. Perret. D. Morris, L. Franchomme-Fosse, R. Cote, S. Fafard, V. Aimez, J. Beauvais, Phys. Rev. B 62, $5092(2000)$ 